\title{
Association Cervix Cancer and Pregnancy: About Eight Cases at Aristide Ledantec Hospital, Dakar, Senegal
}

\author{
Moussa Diallo*, Hayat Ghozayel, Sidy Ka, Ollo Roland Some, Nayi Zongo and Ahmadou Dem \\ Service de Gynécologie - Obstétrique, Centre Hospitalier National de Pikine, Sénégal
}

Submission: April 30, 2019 ; Published: May 09, 2019

*Corresponding author: Moussa Diallo, Service de Gynécologie - Obstétrique, Centre Hospitalier National de Pikine, Sénégal

\begin{abstract}
Cervical cancer is one of the most common malignant diseases encountered during pregnancy. Its incidence during pregnancy is 1.6 to 10.6/10 000 pregnancies, and the highest rates are found in countries with a high birth rate. Our study aimed to study, through eight, the epidemiological, clinical and therapeutic aspects of this doubly morbid association.

Patients and method: This was a retrospective, descriptive study conducted at the Joliot Curie Institute in Dakar from January 2000 to December 2007. We selected patients who had cervical cancer confirmed by an anatomopathological examination discovered either during the pregnancy, either in the postpartum period or after an abortion. We did not include pregnant women whose cervical lesions were not confirmed by pathological examination.
\end{abstract}

Results: Eight patients were definitively retained. Their average age was 30 years with extremes of 24 and 35 years old. The ulcero-budding aspect was the most frequently found (50\%). The common histological type was squamous cell carcinoma. The outcome of the pregnancy was variable. For five patients, the cancer was discovered after twenty weeks of pregnancy, for one patient before twenty weeks and for last one case discovered at three months in the postpartum. The outcome of the pregnancy was variable, three patients had delivered by caesarean section, one of which had benefited from a colpohysterectomy with lymphadenectomy, three other patients had given birth vaginally, a patient whose pregnancy ended with a spontaneous abortion. The five-year overall survival was nil.

Conclusion: The association cervical cancer is a pathology doubly morbid. Its frequency should be declining thanks to all the means of screening we have associated with vaccination against the human papillomavirus. Lethality always remains high.

Keywords: Cervical cancer; Pregnancy; HPV; Lethality

\section{Introduction}

Cervical cancer associated with pregnancy is defined by the discovery of invasive cancer during pregnancy and up to one year postpartum or abortion. It is one of the most common malignant diseases encountered during pregnancy. The incidence of cervical cancer during pregnancy is 1.6 to $10.6 / 10000$ pregnancies [1]. The highest rates are in developing countries with a high birth rate. Diagnostic delay is unfortunately the rule. Its care remains difficult and the protocols still very discussed in our countries and sometimes nonexistent. It is based on the stage of the disease at the time of diagnosis and the gestational term. Ideally, the treatment should be the least mutilating for the patient, while allowing a continuation of the pregnancy. It is a cancer accessible to cervical-vaginal screening in the first trimester of pregnancy.

\section{Patients and Method}

It was a retrospective, descriptive study involving eight patients with cervical cancer associated with pregnancy, managed in the Joliot Curie Institute of the teaching Hospital Aristide Le Dantec in Dakar. This recruitment was extended from January 2000 to December 2007. Included in this study were all patients with cervical cancer, confirmed by histology, either during pregnancy or postpartum, after an abortion. Those whose cervical lesions did not have histological confirmation were not included. The data was collected on a data sheet and processed by the Microsoft Office Excel for Windows software. Our study suffered from the absence of some data not mentioned in the files, of the absence of fixed protocol and the losses of sight during treatment.

\section{Résults}

Eight $(0,008 \%)$ of our patients (975 patients in all) who had cervical cancer with histology were pregnant. The average age at diagnosis was 30 years with extremes of 24 and 35 years. The average gestational age was five, with extremes of four and eight. 
With an average parity of four, and extremes of three and six. The age at first intercourse specified in six of our patients was an average of fifteen with extremes of ten and twenty one years, and that at which the first pregnancy of sixteen had occurred with extremes of fourteen and twenty-two years. Two of our patients had more than two sexual partners. Only one patient had used oral contraception for one year. The metrorrhagia was the most common sign leading to the diagnosis (100\%), they were associated with either hydrorrhea or pelvic pain. The ulcero-budding aspect was the most frequently found (50\%). The histological type was common, it was a squamous cell carcinoma, three of which were moderately differentiated and one with little differentiation, and four cases where the degree of differentiation was not specified. The outcome of the pregnancy was variable, three patients had delivered by caesarean section, one of which had benefited at the time of the cesarean section of a colpohysterectomy with lymphadenectomy, three other patients had given birth vaginally, a patient whose pregnancy was is ended by a spontaneous abortion, and finally one whose outcome was not specified. Among the eight patients, two of them had benefited from an association radiotherapy then surgery, one of the combination of surgery and chemotherapy, another of a chemotherapy alone, one of a surgery alone and finally one of radiotherapy alone. One patient had a local recurrence, metastases were diagnosed in three others. In sum, the five-year overall survival was nil.

\section{Discussion}

\section{Epidemiological aspects and risk factors}

Cervical cancer occurs in $30 \%$ of cases in women during periods of genital activity. Cervical cancer associated with pregnancy is defined by the discovery of invasive cancer of the cervix during pregnancy and up to one year postpartum. The discovery of cervical cancer during pregnancy is a rare situation, and the same is true for all gynecological cancers, with a frequency of $3 \%$ [2]. The incidence of cervical cancer during pregnancy is 1.6 to $10.6 / 10000$ pregnancies [1]. This incidence is very difficult to assess and suffers from several problems including the type of maternity recruitment and the age of the populations. To date, the incidence of this doubly morbid association tends to increase because of the recommendation by the "National Technical Group for Cervical Cancer Screening" to perform a systematic smear in early pregnancy in patients having not been screened in the past three years. Several risk factors have been identified for this cancer. Among them, and probably the most important, infection with the human papillomavirus (HPV). It precedes by twenty years the cancer itself. It is transmitted sexually. Several serotypes are of our always known, some being oncogenes responsible for high grade epithelial lesions.

These are serotypes $16,18,31,33,35,45$ and 51. This infection primarily affects young women aged 20 to 30 years and is acquired within two years after the first sexual intercourse. The target being the squamous cells of the junction cylindrosquamous especially fragile because of the important reshuffles that occur there especially if an ectropion exists. Which is the rule during pregnancy. The precocity of sexual intercourse and the multiple sexual partners expose to this infection. In more than $90 \%$ of cases it heals spontaneously, and in about 3 to $10 \%$ of cases evolves to precancerous lesions or even cancer, through an integration of the genome of the virus to that of the cells of the cylindro-squamous junction. The cicatrization of this ectropion sometimes gives rise to squamous metaplasia of the columnar epithelium, and its vitiation is at the origin of precancerous lesions. In our series, although viral research has not been done, there is every reason to believe that this infection is the primum movens.

In addition, the age of the first sexual intercourse and the first pregnancy are particularly interesting parameters to take into account in our regions, because of our customs, and are also related to the HPV infection. In our series, their average age at diagnosis was 30 years, with extremes of 24 and 35 years, about 20 years younger than for non-pregnant women. These results could be explained in our regions by an early age of women at the time of marriage and consequently, a young age of the first sexual intercourse and the first pregnancy. The age of the patients at the time of diagnosis, in the literature, ranges from 19 to 46 years with an average of between 31 and 34 years; 16 years younger than non-pregnant patients [3].

Note the high parity rank, four to five according to studies [4], a direct consequence of the early marriage. The parity factor is involved in the mechanism of occurrence of cervical cancer through microtrauma suffered by the cervix after each delivery. This is directly related to the age factor. According to Kirch, the parity of patients with this association was five, and it was two for non-pregnant women [5]. In addition, it seems that, compared to nulliparous women, those who had three or four children, have a risk of 2.6 to contract cervical cancer; those with seven or more were 3.8 times more likely than nulliparas [6]. These data from the literature on the role of multiparity in the occurrence of cervical cancer are consistent with those of our series. Gestation poses a double problem. On the one hand, it can be considered as a cofactor related to uncontrolled sexual activity or unplanned maternity [7]; and on the other hand, appears as a factor in itself due to the action of pregnancy on local defense mechanisms, and changes in the cervical epithelium during the pregnancy period [8]. The average gestationality was five in our series, with extremes of four and eight. Gestationality and parity are factors directly related to sexual behavior. Indeed, the risk for a woman to develop cervical cancer depends not only on her sexual behavior but also that of her partner (s) [9]. It is recognized that women from a monogamous matrimonial regime whose husband had several other sexual partners were two to eight times more likely to develop the disease. All these findings are in favor of an infectious factor on which the onset of cancer depends. The earlier the sexual activity, the more the risk increases. This favors a kind of window of vulnerability for the latter longer [10]. In our series, the mean age of onset of 
sexual activity was 15 years with extremes of 10 and 21 . Twenty five percent $(25 \%)$ of our patients had more than two sexual partners. Fifty percent (50\%) of our patients were under 18 years. The first pregnancy, meanwhile, occurred on average at age 16 with extreme ages of 14 and 22 years.

Hormonal status was a minor factor in our series, on the one hand, because the histological type common to all our patients was squamous cell carcinoma, which is not normally hormone-dependent, and on the other hand the fact that only one of our patients had used hormonal contraception during a period of one year. However, this hormonal contraception may be used if it is prolonged, and is associated with HPV infection for squamous cell carcinoma [11] and cervical adenocarcinoma [12]. Immunosuppression, mainly induced by infection with the human immunodeficiency virus, plays a role in the occurrence of precancerous lesions and invasive cervical cancer. To date, cervical cancer in HIV-positive people classifies them directly at the AIDS stage. HIV serology was not requested in our patients. Other infections would play a role in the occurrence of precancerous lesions, mainly herpes simplex virus type 2, and genital chlamydia. These infections would be favored by the low socio-economic level. This hypothesis would be all the more plausible if it is associated with malnutrition. Seven of our patients lived in rural areas.

\section{Diagnostic aspects}

All the problems posed by the management of cervical cancers associated with pregnancy are a reflection of the late diagnosis. Indeed, dysplasia lesions during this period are found in only $1 \%$ of cases. On the other hand, symptomatic cancer is more common. The events leading to consultation are metrorrhagia caused mainly by coitus or examination during a prenatal consultation, more rarely pelvic pain. These symptoms, even if they dominate the circumstances of discovery, are difficult to interpret at this period of pregnancy. Thus the average time between the first symptom and the formal diagnosis is one of 4 to 5 months in about $60 \%$ of cases [13]. This is paradoxical because of the systematization of speculum examination during prenatal visits and Pap smear in the first third. The average consultation time in our series was 5 months higher, consistent with the literature data. All of our patients had macroscopically visible lesions with an ulcerative-vegetative appearance in $50 \%$. The parameters were clinically invaded in seven of our eight patients; of course, this assessment remains unreliable with ligamentous hyperlaxity secondary to pregnancy. The histological type was squamous cell carcinoma in $100 \%$ of cases. And the complication rate, although feared, was zero after the biopsy in our series. In our series, $37 \%$ were classified as Stage II, and $25 \%$ as Stage IVA. This can be explained by the number and the quality of antenatal care that is insufficient compared to what is found in developed countries where the proportion of early stages is higher during pregnancy-related mortality [14]. MRI which is the most appropriate examination for the extension of the disease and the precision of the tumor size could not be realized in our patients because of its high cost. However, two of our patients had metastatic cancer.

\section{Therapeutic aspects}

The treatment depends on the stage of the disease according to the International Federation of Gynecology and Obstetrics (FIGO), the tumor size, the histological type of the tumor, the term of pregnancy and the desire of the couple to preserve the pregnancy (if it seems reasonable on the cancer scene). This management should only be considered after multidisciplinary consultation including oncologist, obstetrician, surgeon, radio and chemotherapist. This in order to make the best decision for the mother and the fetus without delay in the therapeutic procedure. The recommendations recommend that the lesions that are extirpable during caesarean section should be treated without delay, if the fetal maturity is considered as acquired, by performing a colpohysterectomy with pelvic lymphadenectomy, with a trained team [15].

It is admitted that before fetal maturity, between 20 and 24 weeks, (time to which the pelvic laparoscopic lymphadenectomy first seems feasible) for tumors classified IB 1 of less than $2 \mathrm{~cm}$, a laparoscopy first is required for a lymphadenectomy in pergravidic. In the absence of lymph node involvement, regular MRI monitoring is required while waiting for fetal maturation. Once reached, the delivery will be performed by caesarean section with at the same time radical hysterectomy with a node staging. If the lymph nodes are invaded, a therapeutic interruption of the pregnancy should be proposed and carried out without delay, with a view to considering concomitant radiochemotherapy first after uterine emptiness. After 24 weeks, (term where pelvic lymphadenectomy is not feasible including trained operators) close monitoring will be done clinical and radiological subject to the absence of lymphadenopathy during the assessment. Cesarean section will be performed as soon as fetal maturity is achieved, followed by a radical hysterectomy with lymph node staging [15]. If the tumor exceeds $4 \mathrm{~cm}$ with an indeterminate lymph node status, the therapeutic attitude will be discussed on a case by case basis. Before 20 to 24 weeks, the treatment is based on radio-chemotherapy first after obtaining uterine emptiness. Beyond this term, the management focuses on the establishment of lymph node status before allowing surveillance, and this after information of the patient on cancer risk. And the treatment will have to wait until the fetal maturity.

In all cases, the preferred route of delivery is caesarean section because vaginal delivery is likely to result in haematogenous dissemination, cervical dystocia and severe postpartum haemorrhage. In our study, five patients had an evolutive pregnancy at the time of diagnosis. Of these, two (40\% of cases) were stage IIB, had a caesarean section at 29 and 32 weeks, one of which was associated with a radical hysterectomy and pelvic lymphadenectomy at the same time for operation. For the pregnancy at 29 weeks, the surgery was done after radiochemotherapy, and the newborn died in the neonatal period. The 
pregnancy resulted in an abortion at 6 weeks ( $20 \%$ of cases) and was classified as Stage IIB by FIGO. Finally we had one patient with an unknown outcome.

The postoperative complications we noted in our series were the occurrence of vesico-vaginal fistula in one case. Post-operative surveillance will be planned every three months for the first two years and then every six months from the third to the fifth year, in search of recurrence. It will be clinical and radiological (MRI). In one of our patients, recurrence was suspected on the basis of clinical examination but without histological confirmation.

Survival in our serie was far from satisfactory. In $37.5 \%$ of cases it was zero at one year. The other patients being lost sight of. These somewhat disappointing results are a reflection of the weakness of the health system with regard to prenatal care. The routine demand for cervico-vaginal smear in all women of reproductive and sexually active age, and extended to pregnant women at the first prenatal consultation. This would help reduce the rate of invasive cervical cancer as is the case in developed countries. In this way, to date, two vaccines effective against infection with the human papillomavirus (oncogenic serotypes) are also available.

\section{Conclusion}

The association cervical cancer and pregnancy is a pathology doubly morbid. Its frequency should be declining thanks to all the methods of screening we have, associated with vaccination against the human papillomavirus. Similarly, highly evolved forms should no longer be seen, but limited access to care greatly reduces the chances of early diagnosis. Lethality always remains high.

\section{References}

1. Douvier S (2003) prise en charge d'une lesion intra-épithéliale du col de l'utérus en cours de grossesse. Gynécologie obstétrique et fertilité 31: 851-855.

2. Morice P, Castaigne D (2005) cancer du col. Pratique en gynécologie obstétrique. édition Masson, Paris, France.
3. Xercavins J, Gil-Moreno A (2002) prise en charge du précoce du cancer du col utérin associé à la grossesse. Encyclopédie Méd Chir Gynécologie, p. 5.

4. Vicens C (2008) prise en charge des volumineux cancers invasifs du col de l'utérus pendant la grossesse. Gynécologie obstétrique et fertilité 36(4): 365-372.

5. Kinch RA (1961) Factors affecting the prognosis of cancer of the cervix in pregnancy. Am J Obst Gynecol 82: 45-51.

6. Munoz N, Franceschi S, Bosetti C (2002) role of parity and human papilloma virus in cervical cancer: the IARC multicentric case-control study. Lancet 359(9312): 1093-1101.

7. Millogo FT, Akotiongam, Lankoande J (2004) depistage du cancer du col utérin dans un district sanitaire (Burkina Faso) par biopsie du col volontaire après application d'acide acétique et de lugol. Bull Soc Path Exot 97: 135 .

8. N'golet A, Koutoupot BR, Lubuele L (2004) Les néoplasies cervicales intra-épithéliales (CIN) à Brazzaville, Congo. Analuse de situation analysis. Ann Pathol 24(4): 324-328.

9. Skegg DC, Corwin PA, PaulC, Doll R (1982) importance of the male factor in the cancer of cervix. Lancet 2(8298): 581-583.

10. Sasco AJ (2002) Epidémiologie du cancer du col de l’utérus. Encycl MMéd Chir, Gynécol, p. 5.

11. Moreno V, Bosch FX, Munoz N, Meijer CJ, Shah KV, et al. (2002) Effect of oral contraceptives on risk of cervical cancer in women with human papillomavirus infection: The IARC Multicentric Case-Control Study. Lancet 359(9312): 1085-1092.

12.Ursin G, Peters RK, Monroe K, Pike MC, d'Ablaing G, et al. (1994) Henderson Oral contraceptive use and adenocarcinoma of cervix. Lancet 344(8934): 1390-1394.

13. Guttilla JC, Querleu D (1993) Cancers gynécologiques et grossesse (à l'exception des cancers du sein). Rev Fr Gynecol Obstet 88: 538-543.

14. Hacker NF, Bereck JS, Lagasse LD, Elsworth HC, Savage EW, et al. (1982) Carcinoma of the cervix associated with pregnancy. Obstet Gynecol 59(6): 735-746.

15. Morice P, Narducci F, Mathevet P, Marret H, Daraï E, et al. (2009) Recommandations de la Société française d’urologie gynécologique, de la Société française de chirurgie pelvienne et du Collège national des gynécologues et obstétriciens français sur la prise en charge des cancers invasifs du col utérin pendant la grossesse. Gynécologie Obstétrique \& Fertilité 37(11-12): 959-963.
Your next submission with Juniper Publishers will reach you the below assets

- Quality Editorial service

- Swift Peer Review

- Reprints availability

- E-prints Service

- Manuscript Podcast for convenient understanding

- Global attainment for your research

- Manuscript accessibility in different formats

( Pdf, E-pub, Full Text, Audio)

- Unceasing customer service

Track the below URL for one-step submission https://juniperpublishers.com/online-submission.php 